\title{
A Novel Test, the Sternomental Distance Ratio, Used as a Predictor of Difficult Laryngoscopy in a Normal Population and in Thyroid Tumor Surgery Patients: A Preliminary Study
}

\author{
Evangelia Kopanaki ${ }^{1}$, Maria Piagkou ${ }^{2}$, Theano Demesticha ${ }^{2}$, Emmanouil Anastassiou $^{1}$, Panagiotis Skandalakis ${ }^{2}$ \\ ${ }^{1}$ Anesthesiology Department, Thriasio General Hospital of Elefsina, Greece, ${ }^{2}$ Department of Anatomy, Medical School, \\ National and Kapodistrian University of Athens, Greece
}

Correspondence: evkopanaki@yahoo.com; Tel.: + 30213202 8000; Fax.: + 302105551243

Received: 11 January 2020; Accepted: 30 April 2020

\begin{abstract}
Objective. The aim of the present preliminary study was to assess whether the sternomental distance ratio (SMDR) could be suitable as a predictor of difficult laryngoscopy, in both normal surgical patients and patients scheduled to undergo thyroid tumor surgery. Methods. Two hundred and twenty-one consecutive adult patients (among them 122 patients with presumed normal airways and 33 patients with thyroid tumors), scheduled to undergo elective surgery under general anesthesia, were included in this study. Physical and airway characteristics, SMDR, difficult laryngoscopy (using Cormack-Lehane scale) and any kind of assisted intubation were assessed. Results. Decreased SMDR demonstrated a strong correlation with difficult laryngoscopy in both thyroid tumor (Kendall's tau-b $-0.578(\mathrm{P}=0.004)$ and normal patients $-0.362(\mathrm{P}<0.001)$. Difficult laryngoscopy was 0 at $\mathrm{SMDR}>1.9$ and $33 \%$ at $\mathrm{SMDR}<1.55(\mathrm{P}<0.001)$. The higher the SMDR was, the better the glottic view obtained. Conclusions. A SMDR $>1.9$ indicates an easy laryngoscopy, whereas SMDR $<1.55$ indicates a difficult one in both thyroid tumor and normal patients. SMDR is an objective test to assess difficult airway in thyroid surgery.
\end{abstract}

Key Words: Laryngoscopy - Sternomental Distance Ratio - Thyroid Surgery - Thyroid Tumor.

\section{Introduction}

Patients undergoing thyroid tumor surgery are at risk of difficult intubation and consequent increased morbidity and mortality (1-5). The rate of difficult laryngoscopy in thyroid surgery patients may range from $6 \%$ up to $9 \%(6,7)$ and head, neck, ear, nose and throat surgeries may account for more than $20 \%$ of malpractice claims related to difficult tracheal intubation (5).

Several predictive tools for difficult laryngoscopy have been proposed, but with limited accuracy (8-10). Sternomental distance and neck extension are two of these predictive tests $(11,12)$. Furthermore, short neck and limited cervical spine extension are among the common (10\% and 16\% respectively) predictors of difficult tracheal intubation recognized in a large closed claims analysis
(5). Combined tests have been reported to be more accurate in predicting difficult laryngoscopy (8$10)$. However, cervical spine mobility is not easy to quantify objectively $(8,12)$. The ratio of the sternomental distance in neutral and full extension head positions combines the aforementioned predictors accurately and objectively.

Inadequate airway assessment can be a significant contributor to patient harm (5), especially in a setting, such as thyroid surgery that may lead to an increased incidence of difficult intubation (6). No single predictive test that identifies difficult laryngoscopy and correlates well with both "normal" subjects and thyroid surgery patients has yet been found.

The aim of the present preliminary study was to assess whether the sternomental distance ratio 
(SMDR) could be a suitable predictor of difficult laryngoscopy in both normal patients and patients scheduled to undergo thyroid tumor surgery.

\section{Methods}

This masked, preliminary study included 221 consecutive adult patients from 29/05/2013 to $02 / 11 / 2013$, scheduled to undergo elective surgery under general anesthesia, and was performed in a secondary general hospital, the Thriasion General Hospital of Elefsina, Greece. Individual written informed consent was obtained, as well as institutional Ethics Committee approval (Nr 01/17-012013). Pregnant patients, minors, emergency cases, American Society of Anesthesiologists (ASA) status IV patients, and patients with a history of failed or difficult tracheal intubation were excluded from the study. Preoperative patient assessment was performed by a senior anesthesiologist blinded to the study interventions.

The following variables were recorded on a separate sheet for the study purposes: age, gender, body mass index (BMI), Mallampati classification (Mall), upper lip bite test (ULBT), thyromental distance (TMD), and type of surgery. Furthermore, the sternomental distance (the distance from the mentum to the sternal notch) was measured in two different positions: with the neck in full extension as classically described (10), and in a neutral position. The ratio was recorded of the full neck extension sternomental distance to the neutral position sternomental distance. This variable was named the SMDR (Figures 1 and 2).

All patients fasted preoperatively, as per the European Society of Anaesthesiology (ESA) guidelines (13). Standard monitoring, including ECG, $\mathrm{SpO}_{2}$ and NIBP, was applied to all patients, and an $18 \mathrm{G}$ intravenous cannula was inserted. Muscle relaxation was assessed with train-of-four (TOF) monitoring using a peripheral nerve stimulator (Innervator 252, Fisher \& Paykel Electronics Ltd, Auckland, New Zealand) placed in the ulnar nerve. Premedication with intravenous midazolam 1-2 mg was administered to all patients. Preoxygenation was performed with $100 \% \mathrm{O}_{2}$ via face

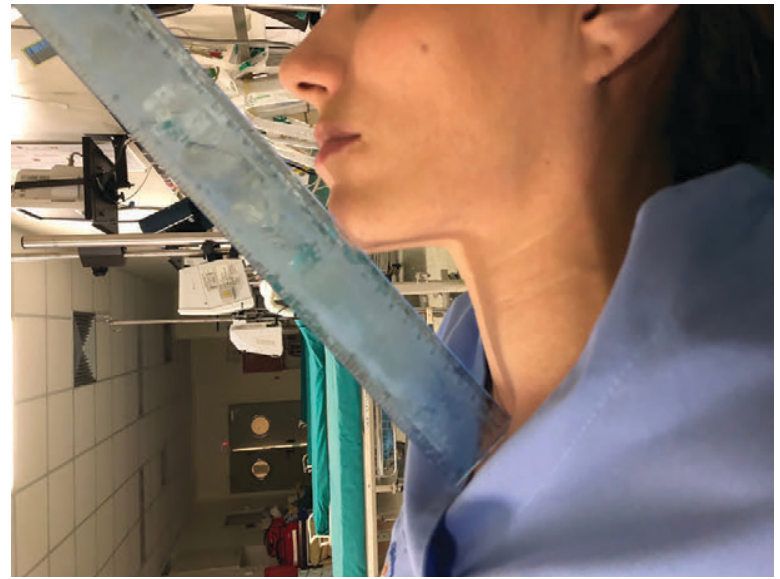

Figure 1. Sternomental Distance in Neutral Head Position.

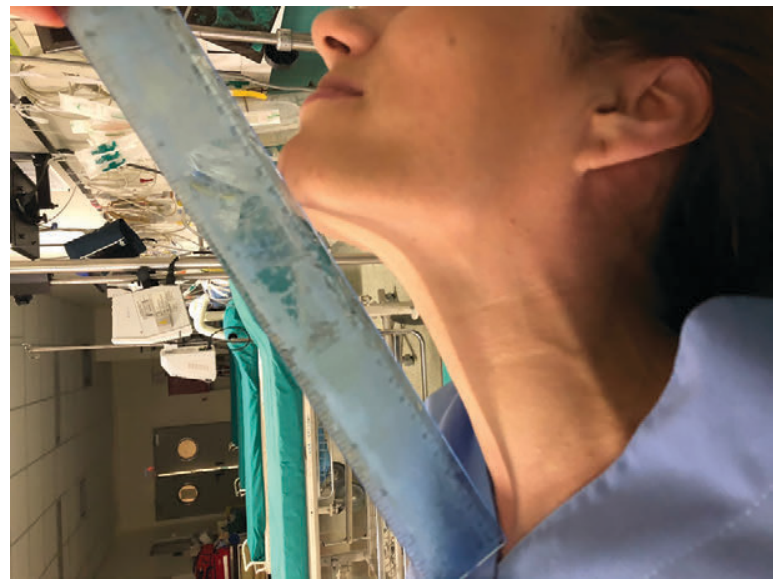

Figure 2. Sternomental Distance in Full Neck Extension.

mask; anesthesia was induced with propofol (2-3 mg. $\left.\mathrm{kg}^{-1}\right)$ and fentanyl (1-2 $\left.\mu \mathrm{g} \cdot \mathrm{kg}^{-1}\right)$. Rocuronium $0.6 \mathrm{mg} . \mathrm{kg}^{-1}$ was administered for tracheal intubation. After adequate muscle relaxation had been achieved, as assessed by a TOF value of 0 in the nerve stimulator, laryngoscopy was attempted by a second senior anesthesiologist, blinded to the airway assessment and the study protocol. The Cormack/Lehane (C/L) scoring system was used to assess the glottic views obtained during laryngoscopy (14). Any aiding technique, such as external laryngeal pressure, backwards-upwards-rightwards manoeuver, gum elastic bougie, change of anesthetist, $3^{\text {rd }}$ attempt with a video-laryngoscope, was recorded as "assisted intubation" for the study purposes. 


\section{Statistical Analysis}

Continuous variables are presented as mean values \pm standard deviation, whereas categorical variables are presented as absolute and relative (\%) frequencies. The association between normally distributed continuous variables and binary variables categories was evaluated through Student's t-test for independent samples. In the case of categorical variables with $>2$ categories, one-way analysis of variance (ANOVA), was applied after checking for homoscedacity. Due to the multiple comparisons, the Bonferroni rule was applied to correct for the inflation of type-I error. Whether these variables were normally distributed was tested through the P-P plot and equality of variances through Levene's test. Associations between categorical variables and sample categories were tested by the use of the chi-squared test. Non-parametric tests (i.e. Spearman's $\rho$ and Kendal's tau-b) were applied to estimate the correlations between SMDR with glottic view. Given the fact that there are no data in the international literature for this predictive factor, the values obtained were divided into 4 quadrants for initial evaluation $(<1.55,1.55-1.72$, $1.73-1.90,>1.90)$ and correlation with somatometrics, indicators of difficult laryngoscopy and glottic views obtained. The receiver operating characteristic (ROC) curve identified the best sensitivity and specificity cut-off point as a SMDR value of 1.7 (Fig. 3). By using the ratio 1.7 as a cut-off point, a binary covariate of SMDR ( $<1.7$ vs. $\geq 1.7)$

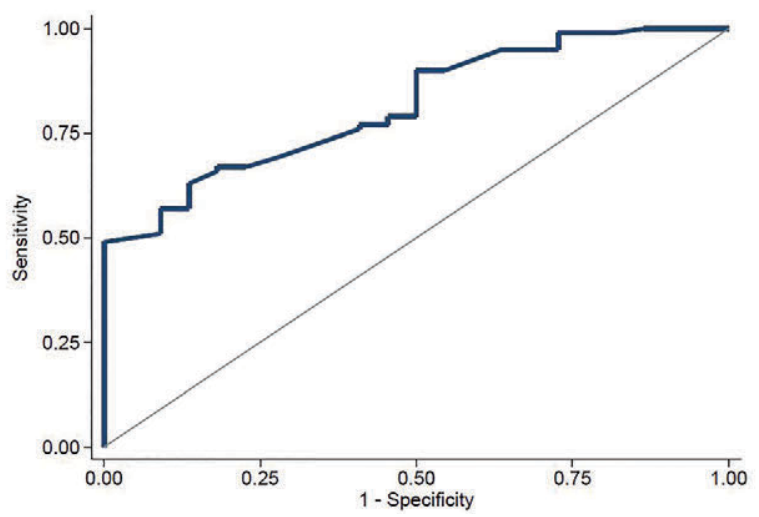

Figure 3. Receiver Operating Characteristic Curve for Sternomental Distance Ratio (SMDR). was created. The statistical calculations were performed on the SPSS version 21 (IBM Hellas, Athens, Greece).

\section{Results}

The study included 221 patients who were all intubated after a maximum 3 attempts and no adverse events. Of the 221 patients, 122 were considered as normal, i.e. not having any visible facial, head and neck deformity during preoperative assessment, and served as a control group for the SMDR test. Of the remaining 99 patients, the second study group comprised 33 patients with thyroid tumors (10 previously operated, and 23 to be operated). The remaining 66 patients were excluded from the present analysis, as they presented characteristics that could influence laryngoscopy (protruding teeth, prognathism and poor dentition).

The characteristics of the study population are presented in Table 1. In the three groups assessed (normal population, previous thyroid tumor surgery and scheduled thyroid tumor surgery), no significant differences were observed in the patients' somatometrics, difficult laryngoscopy indicators, laryngoscopy views, or assisted intubation rates. Furthermore, no significant differences were observed in the SMDR values between normal patients and thyroid surgery patients.

The SMDR values obtained from the patients were divided into four groups, as mentioned in the Methods section (Table 2). It appeared that the higher the SMDR was, the better the glottic view obtained (lower C/L class). A SMDR above 1.9 led to zero assisted intubations and $89 \%$ good or excellent glottic views, whereas when it fell to 1.55 , the good or excellent glottic views fell to $65 \%$ and the rates of assisted intubation accounted for one in three cases (33\%).

When applying a cut-off point of 1.7 for the SMDR, as assessed by ROC analysis, poor or bad glottic views accounted for $13.3 \%$ for SMDR $>1.7$, compared to $48.1 \%$ for SMDR $<1.7$. As depicted in Table 3, according to the Kendall rank correlation coefficient, the binary variable SMDR $(<1.7$ and $>1.7$ ) was significantly negatively correlated with 
Acta Medica Academica 2020;49(3):249-254

Table 1. Patients' Characteristics

\begin{tabular}{|c|c|c|c|c|c|}
\hline \multirow{2}{*}{ Characteristics } & Total & Normal subjects & Previous thyroid tumor surgery & Thyroid tumor surgery & \multirow{2}{*}{$\begin{array}{l}\text { ANOVA } \\
\text { P-value }\end{array}$} \\
\hline & $(n=221)$ & $(n=122)$ & $(n=10)$ & $(n=23)$ & \\
\hline Age, years mean (SD) & $54(17)$ & $45(13)$ & $42(15)$ & $51(12)$ & 0.086 \\
\hline Men number (\%) & $84(38)$ & $41(33.6)$ & $4(40) ; P=0.68$ vs normal & $9(39.1) ; P=0.61$ vs normal & - \\
\hline $\mathrm{BMI}(\mathrm{kg} / \mathrm{m} 2)$ & $27.1(5.1)$ & $26.9(5.5)$ & $23.8(4.7)$ & $29.6(5.1)$ & 0.159 \\
\hline $\operatorname{TMD}(\mathrm{cm})$ & $8.5(1.3)$ & $8.8(1.3)$ & $8.4(1.1)$ & $8.4(1.2)$ & 0.281 \\
\hline SMDR & $1.74(0.28)$ & $1.73(0.26)$ & $1.78(0.31)$ & $1.76(0.22)$ & 0.76 \\
\hline \multicolumn{6}{|l|}{ Upper lip bite test } \\
\hline 1 & $60 \%$ & $56 \%$ & $40 \% ; P=0.33$ vs normal & $52 \% ; P=0.52$ vs normal & _ \\
\hline II & $38 \%$ & $41 \%$ & $60 \% ; P=0.24$ vs normal & $48 \% ; P=0.53$ vs normal & _ \\
\hline III & $2 \%$ & $3 \%$ & $0 \% ; P=0.58$ vs normal & $0 \% ; P=0.40$ vs normal & _ \\
\hline \multicolumn{6}{|l|}{ Mallampati score } \\
\hline 1 & $45 \%$ & $46 \%$ & $40 \% ; P=0.71$ vs normal & $26 \% ; P=0.076$ vs normal & _- \\
\hline II & $39 \%$ & $41 \%$ & $50 \% ; P=0.58$ vs normal & $43 \% ; P=0.86$ vs normal & _ \\
\hline III & $13 \%$ & $12 \%$ & $0 \% ; P=0.25$ vs normal & $22 \% ; P=0.20$ vs normal & - \\
\hline IV & $3 \%$ & $1 \%$ & $10 \% ; P=0.034$ vs normal & $9 \% ; P=0.018$ vs normal & _ \\
\hline \multicolumn{6}{|l|}{ Glottic view } \\
\hline 1 & $50 \%$ & $43 \%$ & $60 \% ; P=0.30$ vs normal & $48 \% ; P=0.65$ vs normal & _ \\
\hline II & $21 \%$ & $25 \%$ & $10 \% ; P=0.28$ vs normal & $18 \% ; P=0.47$ vs normal & _- \\
\hline III & $27 \%$ & $30 \%$ & $30 \% ; P=1.0$ vs normal & $30 \% ; P=1.0$ vs normal & __ \\
\hline IV & $2 \%$ & $2 \%$ & $0 \% ; P=0.65$ vs normal & $4 \% ; P=0.56$ vs normal & _- \\
\hline Assisted intubation & $16 \%$ & $18 \%$ & $20 \% ; P=0.88$ vs normal & $17 \% ; P=0.91$ vs normal & _- \\
\hline
\end{tabular}

$\mathrm{SD}=$ Standard Deviation; $\mathrm{BMI}=$ Body mass index; $\mathrm{TMD}=$ Thyromental distance; SMDR=Sternomental distance ratio.

Table 2. Patients' Characteristics according to Different SMDR Value Ranges

\begin{tabular}{|c|c|c|c|c|c|}
\hline \multicolumn{6}{|l|}{ Patients' characteristics } \\
\hline SMDR & $>1.90$ & $1.90-1.73$ & $1.72-1.55$ & $<1.55$ & \multirow{2}{*}{ P-value } \\
\hline Number & $(\mathrm{N}=53)$ & $(\mathrm{N}=56)$ & $(\mathrm{N}=57)$ & $(\mathrm{N}=55)$ & \\
\hline Mean \% & 38 & 27 & 40 & 47 & 0.16 \\
\hline BMI kg/m² mean (SD) & $27.6(4.8)$ & $26.7(5.3)$ & $26.6(5.1)$ & $27.6(5.3)$ & 0.65 \\
\hline TMD cm, mean (SD) & $8.4(1.2)$ & $8.4(1.3)$ & $8.8(1.3)$ & $8.5(1.5)$ & 0.38 \\
\hline \multicolumn{6}{|l|}{ Upper Lip Bite Test } \\
\hline 1 & $68(\%)$ & $68(\%)$ & $56(\%)$ & $49(\%)$ & 0.27 \\
\hline II & $30(\%)$ & $32(\%)$ & $40(\%)$ & $49(\%)$ & 0.27 \\
\hline III & $2(\%)$ & $0(\%)$ & $4(\%)$ & $2(\%)$ & 0.27 \\
\hline \multicolumn{6}{|l|}{ ASA Status } \\
\hline ASA I & $43(\%)$ & $48(\%)$ & $55(\%)$ & $49(\%)$ & 0.42 \\
\hline ASA II & $49(\%)$ & $45(\%)$ & $33(\%)$ & $35(\%)$ & 0.42 \\
\hline ASA III & $8(\%)$ & $7(\%)$ & $12(\%)$ & $16(\%)$ & 0.42 \\
\hline \multicolumn{6}{|l|}{ Mallampati Score } \\
\hline 1 & $55(\%)$ & $50(\%)$ & $44(\%)$ & $33(\%)$ & 0.33 \\
\hline II & $32(\%)$ & $38(\%)$ & $35(\%)$ & $49(\%)$ & 0.33 \\
\hline III & $9(\%)$ & $12(\%)$ & $14(\%)$ & $15(\%)$ & 0.33 \\
\hline IV & $4(\%)$ & 0 & $7(\%)$ & $3(\%)$ & 0.33 \\
\hline \multicolumn{6}{|c|}{ Cormack/Lehane Glottic View } \\
\hline 1 & $66(\%)$ & $59(\%)$ & $47(\%)$ & $29(\%)$ & $<0.001$ \\
\hline II & $23(\%)$ & $27(\%)$ & $16(\%)$ & $18(\%)$ & $<0.001$ \\
\hline III & $11(\%)$ & $14(\%)$ & $35(\%)$ & $47(\%)$ & $<0.001$ \\
\hline IV & 0 & 0 & $2(\%)$ & $6(\%)$ & $<0.001$ \\
\hline Assisted intubation & 0 & $7(\%)$ & $25(\%)$ & $33(\%)$ & $<0.001$ \\
\hline
\end{tabular}

SMDR=Sternomental Distance Ratio; BMI= Body Mass Index; SD=Standard Deviation; TMD=Thyromental Distance. 
Table 3. Rank Correlation between SMDR with the Cormack/Lehane Scores, in the Total Sample and in Study Subgroups

\begin{tabular}{lllll}
\hline $\begin{array}{l}\text { Kendall's tau-b } \\
(\mathrm{P} \text {-value })\end{array}$ & $\begin{array}{l}\text { Total population } \\
(\mathrm{N}=221)\end{array}$ & $\begin{array}{l}\text { Normal subjects } \\
(\mathrm{N}=122)\end{array}$ & $\begin{array}{l}\text { Previous thyroid surgery } \\
(\mathrm{N}=10)\end{array}$ & $\begin{array}{l}\text { Thyroid tumor surgery } \\
(\mathrm{N}=23)\end{array}$ \\
\cline { 2 - 4 } & Sternomental distance ratio & & \\
\hline Cormack/Lehane & -0.356 & -0.362 & -0.420 & -0.578 \\
(Glottic view) & $(\mathrm{P}<0.001)$ & $(\mathrm{P}<0.001)$ & $(\mathrm{P}=0.19)$ & $(\mathrm{P}=0.004)$ \\
\hline
\end{tabular}

the Cormack/Lehane scores (glottic views). In other terms, the higher the SMDR, the lower the $\mathrm{C} / \mathrm{L}$ score, hence the better the glottic view.

Furthermore, this also seemed to apply for the patients scheduled to undergo thyroid tumor surgery. This correlation also existed for the patients who had already undergone thyroid surgery, although it was not significant, probably due to the small sample.

\section{Discussion}

Numerous preoperative tests are continuously being proposed and assessed in order to predict difficult laryngoscopy, particularly in especially challenging settings, such as thyroid surgery (15). Sternomental distance has been proposed as a good predictor for difficult laryngoscopy, but various cut-off points have been proposed without being sufficiently accurate (16). The same applies for cervical spine movement $(8-10,12)$. The incidence of difficult airways in thyroid surgery varies widely (from $5.3 \%$ to $13.6 \%$ ), depending on the report (17-21).

In the present study, in thyroid surgery patients there were extremely poor glottic views in $4 \%$, and the rate of assisted intubation was $11 \%$. However, these results are not comparable for several reasons. First of all, none of the samples in the aforementioned studies was homogenous. The patients included in these studies varied from simple thyroid nodule cases to extremely large goiters.

SMDR has the advantage of combining neck height, neck mobility and mandibular space, in an accurate and objective way. In the present sample no differences were identified in the rates of difficult laryngoscopy or assisted intubation between patients undergoing thyroid surgery and other patients. However, this was not the aim of the study, but to assess whether the SMDR would correlate with difficult laryngoscopy in both thyroid tumor surgery and normal airway patients. In the present study, a SMDR value below 1.55 led to $53 \%$ of poor laryngoscopic views, whereas a SMDR value above 1.9 almost certainly led to an easy laryngoscopy in all types of patients, including thyroid tumor surgery patients.

An important limitation of the present study (as in all preliminary studies) is its small sample, and the fact that no sample size calculation was performed. Furthermore, regarding the methodology of the study, in order to better evaluate the prognostic performance of SMDR, a simultaneous comparison with a combination of several predictive tests could perhaps also have been undertaken. Of course, this additional set of variables would require an even larger sample, but would have provided more conclusive results.

\section{Conclusions}

SMDR is a quick and objective test to assess a patient's airway. In this preliminary study, SMDR appeared to correlate significantly with difficult laryngoscopy in both normal and in thyroid tumor patients. However, larger studies are necessary in order to provide further data.

\section{What Is Already Known on this Topic:}

Patients undergoing thyroid tumor surgery are at risk of difficult intubation and consequent increased morbidity and mortality. Several predictive tools for difficult laryngoscopy have been proposed, but with limited accuracy. A recent study reported that sternomental distance difference in neutral head position and in full neck extension could be a good predictor of difficult laryngoscopy.

What this Study Adds:

A cut-off point based on a distance difference is very difficult to define, whereas a cut-off point based on an analogy may be easier to assess. In the present study, a sternomental distance ratio $(S M D R)>1.9$ indicated 
an easy laryngoscopy whereas a $S M D R<1.55$ indicated a difficult one in both thyroid tumor and normal patients. SMDR is an objective test to assess difficult airway in thyroid surgery. This is the first study assessing this novel predictor of difficult laryngoscopy in thyroid surgery patients.

Authors' Contributions: Conception and design: EK, EA, TD and PS; Acquisition, analysis and interpretation of data: EK, EA and MP; Drafting the article EK and MP; Revising it critically for important intellectual content: MP and TD; Approved final version of the manuscript: TD and PS.

Conflict of Interest: The authors declare that they have no conflict of interest.

\section{References}

1. Bacuzzi A, Dionigi G, Del Bosco A, Cantone G, Sansone T, Di Losa E, et al. Anaesthesia for thyroid surgery: perioperative management. Int J Surg. 2008;6(Suppl1):S82-5.

2. Dempsey GA, Snell JA, Coathup R, Jones TM. Anaesthesia for massive retrosternal thyroidectomy in a tertiary referral centre. Br J Anaesth. 2013;111(4):594-9.

3. Peterson GN, Domino KB, Caplan RA, Posner KL, Lee LA, Cheney FW. Management of the difficult airway: a closed claims analysis. Anesthesiology. 2005;103(1):33-9.

4. Hisham AN, Roshilla H, Amri N, Aina EN. Post-thyroidectomy Sore Throat Following Endotracheal Intubation. ANZ J Surg. 2001;71(11):669-71.

5. Joffe AM, Aziz MF, Posner KL, Duggan LV, Mincer SL, Domino KB. Management of Difficult Tracheal Intubation: A Closed Claims Analysis. Anesthesiology. 2019;131(4):818-29.

6. De Cassai A, Boscolo A, Rose K, Carron M, Navalesi P. Predictive Parameters of Difficult Intubation in Thyroid Surgery: A Meta-Analysis. Minerva Anestesiol. 2020;86(3):317-26.

7. Kalezić N, Sabljak V, Stevanović K, Milicić B, Marković D, Tošković A, et al. Predictors of difficult airway management in thyroid surgery: a five-year observational singlecenter prospective study. Acta Clin Croat. 2016;55(Suppl 1):S9-18.

8. Roth D, Pace NL, Lee A, Hovhannisyan K, Warenits AM, Arrich J, et al. Airway physical examination tests for detection of difficult airway management in apparently normal adult patients. Cochrane Database Syst Rev. 2018;5:CD008874.

9. Chhina AK, Jain R, Gautam PL, Garg J, Singh N, Grewal A. Formulation of a multivariate predictive model for dif- ficult intubation: A double blinded prospective study. J Anaesthesiol Clin Pharmacol. 2018;34(1):62-7.

10. Detsky ME, Jivraj N, Adhikari NK, Friedrich JO, Pinto R, Simel DL, et al. Will This Patient Be Difficult to Intubate?: The Rational Clinical Examination Systematic Review. JAMA. 2019;321(5):493-503.

11. Savva D. Prediction of difficult tracheal intubation. Br J Anaesth. 1994;73(2):149-53.

12. Ji SM, Moon EJ, Kim TJ, Yi JW, Seo H, Lee BJ. Correlation between modified LEMON score and intubation difficulty in adult trauma patients undergoing emergency surgery. World J Emerg Surg. 2018;13:33.

13. De Hert S, Imberger G, Carlisle J, Diemunsch P, Fritsch G, Moppett I, et al. Task Force on Preoperative Evaluation of the Adult Noncardiac Surgery Patient of the European Society of Anaesthesiology. Preoperative evaluation of the adult patient undergoing noncardiac surgery: guidelines from the European Society of Anaesthesiology. Eur J Anaesthesiol. 2011;28(10):684-722.

14. Cormack RS, Lehane J. Difficult tracheal intubation in obstretics. Anaesthesia. 1984;39(11):1105-11.

15. De Cassai A, Papaccio F, Betteto G, Schiavolin C, Iacobone M, Carron M. Prediction of difficult tracheal intubations in thyroid surgery. Predictive value of neck circumference to thyromental distance ratio. PLoS One. 2019;14(2):e0212976.

16. Prakash S, Mullick P, Bhandari S, Kumar A, Gogia AR, Singh R. Sternomental distance and sternomental displacement as predictors of difficult laryngoscopy and intubation in adult patients. Saudi J Anaesth. 2017;11(3):2738.

17. Bouaggad A, Nejmi SE, Bouderka MA, Abbassi O. Prediction of difficult tracheal intubation in thyroid surgery. Anesth Analg. 2004;99(2):603-6.

18. Amathieu R, Smail N, Catineau J, Poloujadoff MP, Samii $\mathrm{K}$, Adnet F. Difficult intubation in thyroid surgery: myth or reality? Anesth Analg. 2006;103(4):965-8.

19. Kalezić N, Milosavljević R, Paunović I, Zivaljević V, Diklić A, Matić D, et al. The incidence of difficult intubation in 2000 patients undergoing thyroid surgery-a single center expirience. Vojnosanit Pregl. 2009;66(5):377-82.

20. Tutuncu AC, Erbabacan E, Teksoz S, Ekici B, Koksal G, Altintas F, et al. The Assessment of Risk Factors for Difficult Intubation in Thyroid Patients. World J Surg. 2018;42(6):1748-53.

21. Loftus PA, Ow TJ, Siegel B, Tassler AB, Smith RV, Schiff BA. Risk factors for perioperative airway difficulty and evaluation of intubation approaches among patients with benign goiter. Ann Otol Rhinol Laryngol. 2014;123(4):279-85. 